\title{
Familial distal dysautonomia
}

\author{
BRIAN ROBINSON,* RALPH JOHNSON, $†$ DAVID ABERNETHY,* \\ LINDA HOLLOWAY* \\ From the Wellington School of Medicine and Departments of Neurology and Pathology, Wellington Hospital,* \\ Wellington, New Zealand, and John Radcliffe Hospital, $\dagger$ Headington, Oxford
}

SUMMARY A patient is described who presented with painful feet on exercise. He had no evidence of peripheral vascular disease but did have anhidrosis and failure of vasodilatation in the hands and feet suggesting peripheral dysautonomia. Examination of his mother and a cousin and clinical histories of blood relatives suggested that his problem was a severe presentation of a familial distal dysautonomia. In other family members this was represented by dry hands and feet and variable vasomotor symptoms. This condition appeared to be autosomal dominant.

Familial dysautonomia has been described in the Riley-Day syndrome, in which it occurs in infants and young children of Jewish extraction.' It has also been reported in multiple system atrophy in which it presents later in life. ${ }^{2}$ In these disorders the autonomic abnormality is predominantly central in origin. Familial autonomic dysfunction of a peripheral type, affecting sweating and vasomotor activity, has been reported in families in which sensory loss is the predominant feature. ${ }^{3}$ We report a family in which peripheral dysautonomic features were the major cause of presentation without clinical evidence of a sensory disturbance apart from the presenting patient, who suffered from "burning feet". Another family has been described in which "burning feet" was the presenting symptom but in the affected patients there was sensory loss alone. ${ }^{4}$ Our findings indicate that distal autonomic dysfunction may occur as a familial disorder.

\section{Family histories}

The presenting patient (subject 1) and three other blood relatives were examined. Subjects 2 and 3 were the mother and a cousin of subject 1 and subject 4 was his father. It was not possible to examine other members of the family because of the distance they lived from Wellington, but clinical histories were obtained on 17 blood relatives in three generations: the inheritance appears to be autosomal dominant (fig 1). No members of the family had a history of diabetes

Correspondence to: R H Johnson, Director, Postgraduate Medical Education, Oxford University, John Radcliffe Hospital, Headington, Oxford OX3 9DU, United Kingdom.

Received 11 November and in revised form 31 January 1989. Accepted 14 July 1989 mellitus, rheumatoid arthritis or chronic alcoholism. None of the affected subjects we studied admitted to any abnormality of sexual function.

\section{Case reports}

Subject 1 A European male, aged 27 years, presented with painful feet and toes from the age of 10 years. Pains occurred with particular severity after exertion (for example running or swimming) and there was a burning sensation around the toe nails. Stabbing pains on the dorsum of each foot could be produced by bending down, crouching or kneeling. Running or hot weather caused his feet to redden and in hot weather his feet would "feel swollen as if there was too much blood in them and they would explode". His other major complaint was of dry skin on the hands and feet and the skin on the feet cracked easily.

On examination he looked well, the hands and feet were dry and there was a lack of hairs on the backs of the hands and below the ankles. There were no other abnormalities on

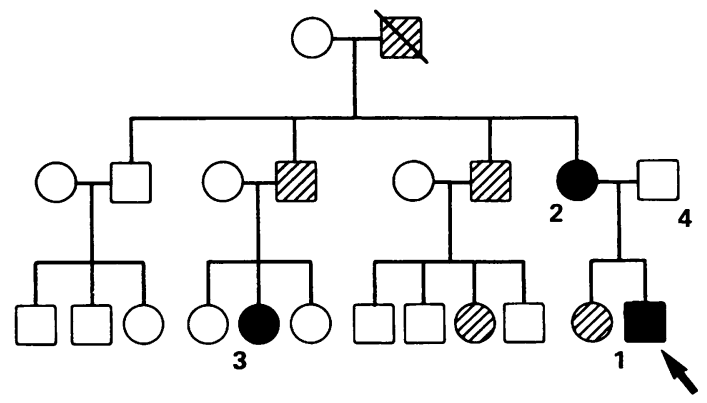

Fig 1 Kinship described in this report. Arrow indicates the presenting case (subject 1). Subjects 2, 3, and 4 have also been studied and are described in detail. Subjects studied who are affected are shown by the closed circles, other apparently affected relatives are shown by stippling. 
examination. All peripheral pulses were present including that of the dorsalis pedis artery bilaterally. Reflexes were normal and symmetrical. There was no sensory loss. Nerve conduction studies, using previously described techniques and normal ranges, ${ }^{5}$ showed reduced medial plantar and sural potentials consistent with mild axonal neuropathy (table 1). Blood screening tests were all normal (haemoglobin, red cells, white cells, platelets, serology for syphilis, glucose, proteins and immuno-globulins, vitamin $B_{12}$, serum and red cell folate, complement and autoantibodies); urine lead levels ( $0.05 \mu \mathrm{mol} / \mathrm{l})$ were normal (limit $>0.77 \mu \mathrm{mol} / \mathrm{l})$. Studies of cerebrospinal fluid were also normal (total protein $0.43 \mathrm{~g} / \mathrm{l}$ ).

Subject 2 A European female aged 53 years, mother of subject 1 . This patient also had dry feet and hands. Her feet tended to crack easily. The condition had been occurring for as long as the patient could remember. Reflexes and sensation were normal. Nerve conduction studies were normal (table 1).

Subject 3 A European female aged 36 years, cousin of subject 1 , also had dry hands and feet which had occurred for as long as she could remember. Reflexes and sensation were normal. Nerve conduction studies showed a reduced medial plantar potential suggesting an axonal neuropathy (table 1). Subject 4 A European male, aged 57 years, father of subject 1. This patient was unaffected. Reflexes and sensation were all normal. Nerve conduction studies were normal.

Other family members Histories taken from family members suggested five others were similarly affected. Two females, one a sister and the other a cousin of subject 1 , complained of an overall dryness of skin, particularly on the hands and feet, which cracked easily. They "did not sweat much" and this was more so in the hands and feet. Two males, brothers of subject 2, also complained of dry hands and feet which cracked easily. They apparently sweated normally except for the hands and feet where sweating did not occur. Another male, father of subject 2, had been dead for several years but had complained of a similar condition to that described by his two sons.

\section{Autonomic Investigations}

These were carried out in subject 1 and in his father, mother and one cousin (subjects 2-4).
Arterial blood pressure and heart rates were measured lying and standing and were normal as was the 30:15 ratio (R-R interval ratios at 30th and 15th beats after standing). Studies of heart rate responses to Valsalva's manoeuvre, deep breathing, and heart rate and blood pressure responses during isometric forearm exercise were also normal. ${ }^{67}$

Sweating distribution was observed by applying quinizarin powder to the skin. ${ }^{8}$ The subjects were each heated using a radiant heat cradle (six $\times 60 \mathrm{~W}$ lamps). Sweating distribution is shown in fig 2 . In subject 1 there was normal sweating over the face, trunk and axillae but sweating was absent over the arms below the elbows and over the legs below the knees. Subjects 2 and 3 had considerably reduced sweating over the whole body and it was completely absent in the limbs. In subject 4 , the father of the presenting patient, sweating was normal.

Blood flows were studied using Hatfield-Turner coppertellurium heat flow discs on the fingers and toes.' Skin temperature on the finger and toes was recorded using a thermocouple thermometer (Ellab). Central temperature measured at the external auditory meatus or the mouth was also recorded. Observations were made during heating of the trunk by the radiant heat cradle. In the presenting patient, subject 1 , no vasodilatation occurred in either the hands and feet, even after heating for $30 \mathrm{~min}$ (fig 3a). His central temperature had risen to $37.4^{\circ} \mathrm{C}$ at the end of this procedure. In subject 2 , the mother of subject 1 , vasodilatation occurred normally and rapidly in the finger pulps but no vasodilatation occurred in the feet even after 30 minutes radiant heating of the trunk at a central temperature of over $36.5^{\circ} \mathrm{C}$. Subject had very warm hands and a central temperature of $37.0^{\circ} \mathrm{C}$ the rapid vasodilatation in the fingers seen in the previous patient did not occur but this could have been due to the considerable degree of dilatation present at rest. In the feef however, vasodilatation occurred slowly over 10-15 minute beginning after 25-30 minutes of radiant heating Vasodilatation occurred promptly in the hands and feet of subject 4 , father of the presenting subject, at a central temperature of $36.5^{\circ} \mathrm{C}$.

Postganglionic axon reflex activity, which normally produces local sweating and piloerection, was studied around intradermal injections of $1 \%$ acetylcholine solution ${ }^{10} 11$ and no response was obtained in the presenting patient (subject 1 ) and his mother (subject 2); subject 3 was not studied. Skin

Table Sensory and motor nerve conduction studies. Sensory nerve studies used the right sural (RS) and medial plantar (MP) nerves and motor nerve studies used the right lateral popliteal nerve. The normal results for sensory nerves are from Guiloff and Sherratt (1977). Sulfect 1 had reduced sural and medial plantar nerve action potential amplitudes. Subject 3 had a reduced medial plantar nerve action potential amplitude only. All other results are essentially normal.

\begin{tabular}{|c|c|c|c|c|c|c|c|c|c|}
\hline \multicolumn{8}{|c|}{ Sensory nerves } & \multicolumn{2}{|l|}{ Motor nerves } \\
\hline \multirow[b]{2}{*}{ Nerve } & \multicolumn{3}{|c|}{ Amplitude ( $m V)$} & \multicolumn{3}{|c|}{ Latency to onset (ms) } & \multirow{2}{*}{$\begin{array}{l}\text { Conduction } \\
\text { velocity } \\
(\mathrm{m} / \mathrm{s})\end{array}$} & \multirow{2}{*}{$\begin{array}{l}\text { Amplitude of } \\
\text { evoked muscle } \\
\text { potential }(\mathrm{mV})\end{array}$} & \multirow{2}{*}{$\begin{array}{l}\text { Cond } \\
\text { veloci } \\
(\mathrm{m} / \mathrm{s})\end{array}$} \\
\hline & Subject & Normal range & Mean & Subject & Normal range & Mean & & & \\
\hline $1 \underset{\mathrm{MP}}{\mathrm{RS}}$ & $\begin{array}{l}4.2 \\
0.9\end{array}$ & $\begin{array}{l}9 \cdot 2-20 \cdot 0 \\
1 \cdot 7-5 \cdot 5\end{array}$ & $\begin{array}{r}16.0 \\
3.0\end{array}$ & $\begin{array}{l}2.9 \\
5 \cdot 7\end{array}$ & $\begin{array}{l}2 \cdot 4-3 \cdot 5 \\
4 \cdot 1-5 \cdot 5\end{array}$ & $\begin{array}{l}3 \cdot 0 \\
4 \cdot 7\end{array}$ & 48 & 6.5 & 48 \\
\hline $2 \underset{\mathrm{MP}}{\mathrm{RS}}$ & $\begin{array}{l}9 \cdot 5 \\
1 \cdot 2\end{array}$ & $\begin{array}{l}6.0-41.4 \\
1.0-2.8\end{array}$ & $\begin{array}{r}14 \cdot 3 \\
1 \cdot 7\end{array}$ & $\begin{array}{l}3 \cdot 2 \\
4 \cdot 1\end{array}$ & $\begin{array}{l}2.4-3 \cdot 8 \\
4.2-6.0\end{array}$ & $\begin{array}{l}3 \cdot 2 \\
5 \cdot 1\end{array}$ & 43 & - & - \\
\hline $\begin{array}{l}3 \text { RS } \\
\text { MP }\end{array}$ & $\begin{array}{r}10.3 \\
0.8\end{array}$ & $\begin{array}{l}9 \cdot 2-38 \cdot 2 \\
1 \cdot 6-5 \cdot 7\end{array}$ & $\begin{array}{r}23 \cdot 0 \\
3 \cdot 1\end{array}$ & $\begin{array}{l}3 \cdot 1 \\
5 \cdot 0\end{array}$ & $\begin{array}{l}2 \cdot 6-3 \cdot 3 \\
3 \cdot 6-5 \cdot 1\end{array}$ & $\begin{array}{l}3 \cdot 0 \\
4 \cdot 5\end{array}$ & 45 & $4 \cdot 5$ & 48 \\
\hline $\begin{array}{l}4 \text { RS } \\
\text { MP }\end{array}$ & $\begin{array}{l}8.5 \\
1.6\end{array}$ & $\begin{array}{l}6.0-41.4 \\
1.0-2.8\end{array}$ & $\begin{array}{r}14 \cdot 3 \\
1 \cdot 7\end{array}$ & $\begin{array}{l}2 \cdot 8 \\
4 \cdot 2\end{array}$ & $\begin{array}{l}2 \cdot 4-3 \cdot 8 \\
4 \cdot 2-6 \cdot 0\end{array}$ & $\begin{array}{l}3 \cdot 2 \\
5 \cdot 1\end{array}$ & 50 & - & - \\
\hline
\end{tabular}




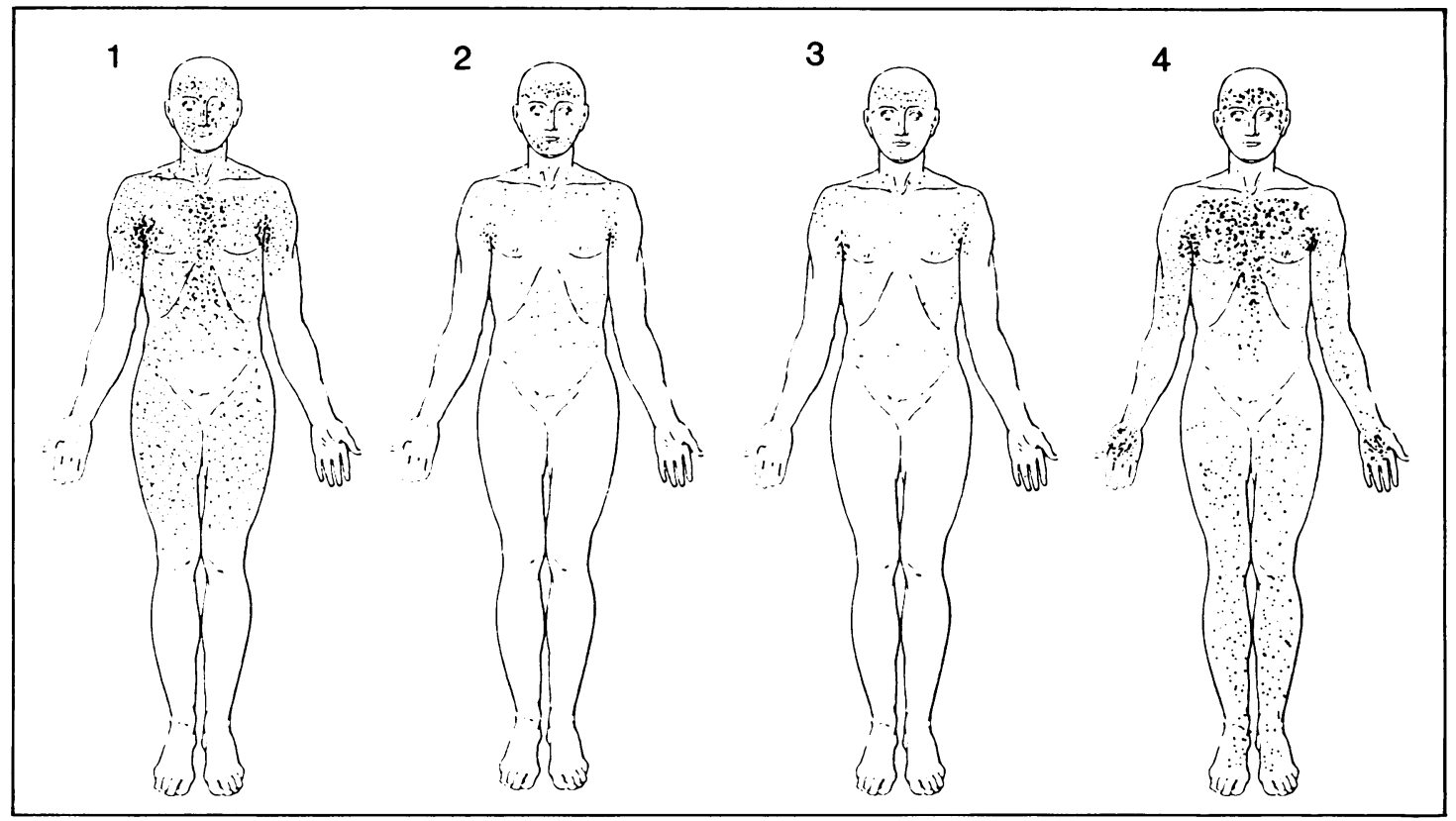

Fig 2 Sweating distribution using quinizarin test. Subject 1 after 29 min heating (central temperature $37 \cdot 4^{\circ} \mathrm{C}$ ); subject 2 after 30 min heating (central temperature $36 \cdot 5^{\circ} \mathrm{C}$ ); subject 3 after 44 min heating (central temperature $37 \cdot 4^{\circ} \mathrm{C}$ ); subject 4 after 25 min heating (central temperature $36 \cdot 6^{\circ} \mathrm{C}$ ).

wrinkling in response to immersion of the hands and feet in warm $\left(40^{\circ} \mathrm{C}\right)$ water was also absent in the affected subjects (subjects 1, 2, 3). ${ }^{12}$

Punch biopsies of skin from affected areas of the forearms and lower legs of subjects 1,2 and 3 were examined for autonomic nerve fibre, sweat gland, hair follicle and blood vessel morphology using enzyme histochemistry ${ }^{13}$ as well as standard haematoxylin and eosin staining. Transmission electron microscopy for noradrenergic granules failed to reveal any. Sections were also examined for peripheral nerve fibres using Palmgren's method ${ }^{14}$ and immuno-peroxidase techniques using commercially available rabbit antisera for S-100 protein and neuron-specific enolase (Dakopatts, Denmark). Sections of skin from the forearms and legs of subject 1 revealed normal sweat gland, hair follicle and blood vessel morphology but there was no evidence of autonomic neural elements. One small peripheral nerve fibre bundle was identified close to a small venule (indicating that the techniques could detect neural elements), however no neural elements were associated with sweat glands or arterioles; neither were autonomic fibres observed in the biopsy specimens from the legs of subjects 2 and 3 . In all three subjects very fine single nerve fibres were identified beneath the epidermis.

Treatment in subject 1: Guanethidine block of lumbar sympathetic nerves was performed twice but was ineffective. Vasodilatation using cyclandelate or nicotinic acid was also ineffective. Carbamazepine was effective in eliminating the pain but it caused a severe rash which made it unacceptable as a treatment. Phenytoin was also ineffective, as was phenoxybenzamine. Percutaneous nerve stimulation produced some short-term relief.

\section{Discussion}

The presenting patient (subject 1) complained of burning, particularly with exercise. This appeared to be related to failure of vasodilatation in the hands and feet. Normally peripheral vasodilatation occurs in response to radiant heating of the trunk when the central temperature is above $36 \cdot 5^{\circ} \mathrm{C} .^{15}$ The failure of vasodilatation to occur in subject 1 when the central temperature was above $37.0^{\circ} \mathrm{C}$ was probably due to an absence of sympathetic cholinergic nerve fibres to blood vessels in the skin. Sweat glands and hair follicles were observed in sections of skin biopsy but pilomotor and sudomotor function was not evident by the response to intradermal injection of acetylcholine $^{1011}$ and no autonomic nerve fibres were observed in biopsy specimens. The presenting patient therefore appears to have a distal autonomic neuropathy. The two other family members examined (subjects 2 and 3) had no sweating in the hands and feet and in both of these a punch skin biopsy failed to reveal autonomic neurons. A minor degree of vasomotor function was, however, intact. Several 
(A) Case 1

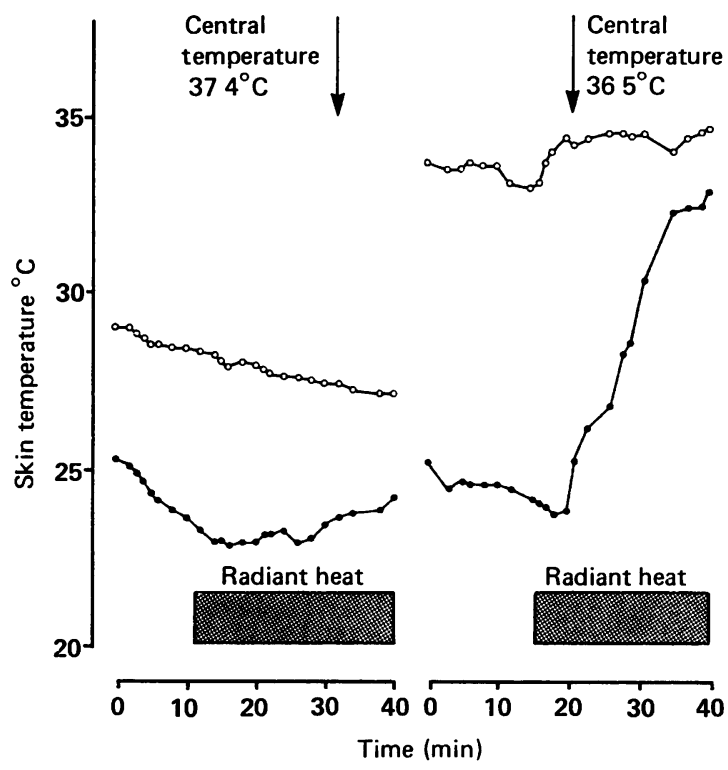

Fig 3 Digit skin temperatures $\left({ }^{\circ} \mathrm{C}\right.$, finger, $\bigcirc$ toe) and central temperature $\left(^{\circ}\right)$ from $(a)$ the presenting patient, subject 1, and (b) his father, subject 4 . The presenting patient did not vasodilate in his digits, even though his central temperature was $37 \cdot 4^{\circ} \mathrm{C}$. His, father who was unaffected, already had warm (dilated) toes at the beginning of the study and vasodilatation occurred normally in his fingers.

other family members were reported to have absent peripheral sweating.

The disorder is therefore an autonomic neuropathy localised in the hands and feet affecting vasomotor, pilomotor and sudomotor function. The glove and stocking distribution of the autonomic abnormalities is similar to that seen in diabetes mellitus, rheumatoid arthritis, and chronic alcoholism. ${ }^{16-18}$ The results of histological investigations $s^{1319}$ and intradermal injection of acetylcholine ${ }^{1011}$ indicate that the lesion is a post-ganglionic sympathetic neuropathy. The absence of vasodilatation during heating is probably due to failure of a release of vasoconstrictor tone by sympathetic cholinergic fibres. ${ }^{20}$ Dyck et al reported a family in which "burning feet" was the major symptom of a dominantly inherited subclinical sensory neuropathy. In their subjects the burning sensation was also aggravated by hot weather, similar to the complaint of our presenting patient, but these authors did not comment on any disturbance of peripheral autonomic function. We suggest that in our patient pain during exercise was due to failure of appropriate vasodilatation and was therefore due to relative ischaemia in muscle groups in the feet.
Although hereditary sweating loss, "congenital anhidrosis", is well described, none of the causes have been attributed to a specific post-ganglionic sympathetic neuropathy similar to that described here. Hereditary anhidrosis due to an absence of sweat gland innervation was described by Swanson ${ }^{21}$ in association with congenital insensitivity to pain. It may also occur in association with a more generalised autonomic neuropathy, sensory loss and mental abnormality. ${ }^{223}$ In familial dysautonomia sweating loss may also occur. ${ }^{2}$ However, the affected cases have evidence of central lesions causing more generalised autonomic disorders such as orthostatic hypotension rather than the more specific lesion we have observed in our subjects.

In reporting this family we wish to draw attention to distal autonomic dysfunction occurring familially with autosomal dominant presentation. This disorder has been observed without sensory or motor signs and only minor evidence of large fibre neuropathy on nerve conduction studies.

We thank the subjects for their cooperation and the Wellington Medical Research Foundation for supporting this study.

\section{References}

1 Riley CM, Day RL, Greeley DM, Langford WS. Central autonomic dysfunction with defective lacrimation: report of 5 cases Pediatrics 1949;3:468-78.

2 Lewis P. Familial orthostatic hypotension. Brain 1964;87: 719-28.

3 Axelrod FB, Pearson J. Congenital sensory neuropathies. Am J Dis Child 1984;138:947-54.

4 Dyck PJ, Low PA, Stevens JC. "Burning feet" as the only manifestation of a dominantly inherited sensory neuropathy. Mayo Clin Proc 1983;58:426-9.

5 Guiloff RJ, Sherratt RM. Sensory conduction in medial plantar nerve. J Neurol Neurosurg Psychiatry 1977;40: 1168-81.

6 Ewing DJ. Practical bedside investigation of diabetic autonomic failure. In: Bannister RG, ed. Autonomic Failure. Oxford: University Press, 1983:371-405.

7 Johnson RH, Lambie DG, Spalding JMK. Neurocardiology: the Interrelationships between dysfunction in the nervous and cardiovascular systems. London: WB Saunders Co, 1984.

8 Guttmann L. Topographic studies of disturbances of sweat secretion after complete lesions of peripheral nerves. J Neurol Psychiatry 1940;3:197-210.

9 Hatfield HS. A heat flow meter. J Physiol 1950;111:10P.

10 Macmillan AC, Spalding JMK. Human sweating response to electrophoresed acetylcholine: a test of postganglionic sympathetic function. J Neurol Neurosurg Psychiatry 1969;32. $155-60$.

11 Johnson RH, Spalding JMK. Disorders of the autonomic nervous system. Oxford: Blackwell Scientific Publications, 1974.

12 O'Riain S. New and simple test of nerve function in hand. Br Med J 1973;3:615-6.

13 Karnovsky MJ, Roots L. A "direct coloring" thiocholine method for cholinesterases. J Histochem Cyctochem 1964;12:219-21.

14 Cox G. Neuropathological techniques. In: Bancroft JD, Stevens A 
eds. Theory and practice of histological techniques. Second Ed. Edinburgh: Churchill Livingstone, 1982:332-63.

15 Cooper KE, Johnson RH, Spalding JMK. The effects of central body temperature and trunk skin temperatures on reflex vasodilatation in the hand. J Physiol 1964;174:46-54.

16 Bárány FR, Cooper EH. Pilomotor and sudomotor innervation in diabetes. Clin Sci 1956;15:533-40.

17 Bennett PH, Scott JT. Autonomic neuropathy in rheumatoid arthritis. Ann Rheum Dis 1965;24:161-8.

18 Low PA, Walsh JC, Huang CY, McLeod JG. The sympathetic nervous system in alcoholic neuropathy: a clinical and pathological study. Brain 1975;98:357-64.

19 Faerman I, Faccio E, Calb I, et al. Autonomic neuropathy in the skin: a histological study of the sympathetic nerve fibres in diabetic anhidrosis. Diabetologia 1982;22:96-9.

20 Coffman JD, Cohen RA. Cholinergic vasodilator mechanism in human fingers. Am J Physiol 1987;252:H594-7.

21 Swanson AG. Congenital insensitivity to pain with anhidrosis. Arch Neurol 1963;8:299-306.

22 Dyck PJ. Neuronal atrophy and degeneration affecting peripheral sensory and autonomic neurons. In: Dyck PJ, Thomas PK, Lambert EH, Bunge R, eds. Peripheral neuropathy. Second Ed. Philadelphia: WB Saunders, 1984:1557-99.

23 Jestico JV, Urry PA, Efphimiou J. An hereditary sensory and autonomic neuropathy transmitted as an X-linked recessive trait. J Neurol Neurosurg Psychiatry 1985;48:1259-64. 